
\title{
25 Research Soure \\ Risk Factors of Rapid Lung Function Decline in COPD Patients of Real World
}

\section{Hyun Woo Lee}

Seoul Metropolitan Government-Seoul National University Boramae Medical Center https://orcid.org/0000-0003-4379-0260

\section{Jung-Kyu Lee}

Seoul Metropolitan Boramae Hospital

\section{Myung Goo Lee}

Hallym University College of Medicine

\section{Kyung-Chul Shin}

Yeungnam University School of Medicine and College of Medicine

\section{Seung Won Ra}

University of Ulsan College of Medicine

\section{Tae-Hyung Kim}

Hanyang University Guri Hospital

\section{Yong il Hwang}

Hallym University Sacred Heart Hospital

\section{Ki-Suck Jung}

Hallym University Sacred Heart Hospital

\section{Kwang Ha Yoo}

Konkuk University Seoul Hospital

\section{Deog Kyeom Kim ( $\nabla$ kimdkmd@gmail.com )}

Seoul Metropolitan Government-Seoul National University Boramae Medical Center

\section{Research}

Keywords: Forced Expiratory Volume, Respiratory Function Tests, Risk Factors, Pulmonary Disease, Chronic Obstructive, Cohort Studies

Posted Date: August 12th, 2021

DOl: https://doi.org/10.21203/rs.3.rs-770874/v1

License: (9) (1) This work is licensed under a Creative Commons Attribution 4.0 International License. Read Full License 


\section{Abstract}

Background: Rapid lung function decliners have been considered a unique subgroup of patients with chronic obstructive pulmonary disease (COPD). A rapid decline manifests early and is related with a poor prognosis. Therefore, pre-emptive identification of risk factors for rapid decliner is necessary. We aimed to determine those risk factors in Korean patients.

Methods: A longitudinal, observational study was conducted on the KOCOSS cohort (NCT02800499), consisting of patients assessed from January 2012 to December 2019 at 54 medical centers in South Korea. Eligible patients were adults followed up for 3 years with serial spirometric tests. We calculated the annualized percentage change in lung function from baseline. Rapid decliners were defined as the quartile of patients with the highest annualized percentage decline in lung function.

Results: Among the 518 included patients, 130 were rapid decliners. Rapid decliners lost $6.2 \% / y e a r$ and $100 \mathrm{ml} /$ year of forced expiratory volume in 1 second from baseline. Rapid decliners had a higher rate of severe exacerbations than non-rapid decliners (0.2/year vs. 0.1/year, $\mathrm{P}=0.032)$. Upon multivariable logistic regression, male sex, being a current smoker, a blood eosinophil count $<150 / \mu \mathrm{l}$, and a high forced vital capacity were independent risk factors for a rapid decline. In rapid decliners, lung function deteriorated more rapidly in current smokers and patients with more severe dyspnea, while triple combination therapy attenuated lung function decline compared to mono-bronchodilator therapy.

Conclusions: Identification of risk and aggravating factors for rapid lung function decline may assist physicians in providing earlier intervention for high-risk patients with COPD.

\section{Background}

Chronic obstructive pulmonary disease (COPD) is characterized by persistent airway inflammation that induces mucus hypersecretion and alveolar wall destruction and contributes to small airway narrowing and deformity $(1-3)$. Higher levels of airway inflammatory mediators are significantly associated with a faster decline in forced expiratory volume in 1 second $\left(\mathrm{FEV}_{1}\right)$ than lower levels, which means a more severe airflow limitation $(4,5)$. Airflow limitation is a hallmark of COPD. The severity of airflow limitation has been graded by using the $\mathrm{FEV}_{1}$ as a percentage of the predicted value and is positively related with symptomatic burden, exacerbation risk, hospitalization, and mortality $(6,7)$. Recently, inhaled pharmacotherapy for patients with COPD has played an important role in reducing the rate of decline in lung function and improving the clinical prognosis $(8,9)$.

However, the natural course of decline in lung function in COPD patients is heterogeneous and should be evaluated in consideration of individual clinical factors. Half of patients with COPD exhibit a more rapid decline in lung function than healthy smokers or non-smokers without COPD, while the other half exhibit impairment during lung development with normal rates of decline in lung function (10). Among patients with COPD, "rapid FEV ${ }_{1}$ decliners" have been considered a unique subgroup, and a rapid $\mathrm{FEV}_{1}$ decline is 
related with high rates of hospitalization and mortality (11). As the rate of lung function decline is reportedly at its peak in mild or early-stage $\operatorname{COPD}(12,13)$, early interventional strategies should be considered for rapid $\mathrm{FEV}_{1}$ decliners.

Therefore, it is necessary to identify risk factors for a rapid lung function decline in patients with COPD. Besides demographic risk factors, including a higher age, a lower body mass index (BMI), being a current smoker, and more severe dyspnea $(11,14)$, frequent or acute exacerbation events are important risk factors for the rapid decline in lung function (15-17). Recent studies indicate that acute exacerbation and a rapid decline in $\mathrm{FEV}_{1}$ are related with high counts of blood eosinophils (18). However, few researchers report the relative decline of lung function (percentage change from baseline FEV 1 per year $[\% /$ year] $)$, rather reporting the absolute decline in lung function $\left(\mathrm{FEV}_{1} \mathrm{ml}\right.$ per year [ml/year]). In addition, the real-world risk factors of being a rapid FEV ${ }_{1}$ decliner in Asian patients with COPD have not been sufficiently elucidated.

Our multicenter, longitudinal study was conducted to investigate the risk factors related to a rapid FEV 1 decline in Korean patients with COPD who underwent spirometric tests for 3 consecutive years.

\section{Methods}

Our study was reported in accordance with the Strengthening the Reporting of Observational Studies in Epidemiology (STROBE) statement (19).

\section{Study design and eligibility criteria}

In this longitudinal, observational study, we made use of the Korea COPD Subgroup Study (KOCOSS) cohort (NCT02800499), a prospective database consisting of patients diagnosed with COPD who were registered from January 2012 to December 2019 at 54 medical centers in South Korea. The methodologic information of the KOCOSS cohort was described in a previous study (20). Diagnosis of COPD was established based on Global Initiative for Chronic Obstructive Lung Disease (GOLD) guidelines, using the

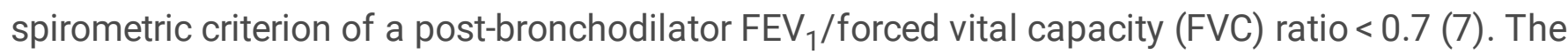
inclusion criteria were patients who 1) were $\geq 40$ years old, 2) underwent spirometry at baseline examination, and 3) were followed up with spirometry for 3 years.

\section{Baseline medical information and clinical outcomes}

At the initial assessment, we obtained the baseline information of the included patients. Detailed medical information included age, sex, BMI, years of education, area of residence, smoking status, Charlson comorbidity index $(\mathrm{CCl})$, and history of lung disease (asthma and tuberculosis). We evaluated baseline symptoms and quality of life with the COPD assessment test (CAT) score, St George's Respiratory Questionnaire for COPD Patients (SGRQ-C) score, and the 6-minute walking distance. We also recorded patients' 1-year history of total and acute exacerbations. 
The study participants underwent baseline spirometric, laboratory, and radiologic tests. In terms of spirometry, post-bronchodilator $\mathrm{FEV}_{1}$ and $\mathrm{FVC}$ ( $\mathrm{ml}$ and $\%$ of the predicted value), diffusing capacity for carbon monoxide (DLCO) (\%), DLCO/alveolar volume (VA) (\%), and total lung capacity ( $\mathrm{ml}$ and \% of the predicted value) were obtained. In terms of laboratory tests, complete and differential counts were evaluated. In terms of radiology, structural abnormalities such as emphysema, bronchiectasis, and tuberculous-destroyed lung were evaluated. We investigated current medication use for COPD management, including inhaled pharmacologic therapy (e.g. long-acting beta-agonist [LABA], long-acting muscarinic antagonist [LAMA], LABA/LAMA, inhaled corticosteroids [ICS]/LABA), phosphodiesterase-4 inhibitor, and methylxanthine.

For evaluation of clinical outcomes, the 3-year total number of moderate or severe exacerbations, annual rate of moderate or severe exacerbations, and number of mortalities were recorded.

\section{Definition of rapid decliners}

We divided the study participants into four quartiles of change in $\mathrm{FEV}_{1}$. We determined the change of $\mathrm{FEV}_{1}$ as an annualized percentage change from the baseline $\mathrm{FEV}_{1}$ in each individual (Supplementary information 1) (11). The group with the most negative change in $\mathrm{FEV}_{1}$ (1st quartile) were defined as rapid decliners. The other quartiles (2nd, 3rd, and 4th quartiles) were defined as non-rapid decliners.

\section{Statistical analyses}

Student's t-test or the Wilcoxon rank-sum test was used to compare continuous variables. The chi-square test or Fisher's exact test was used to compare categorical variables. Univariable and multivariable logistic regression analyses were performed with clinically important confounders related to rapid decliners. A variance inflation factor $<4.0$ was determined as a significant multicollinearity. Sensitivity analysis was conducted in the rapid decliner group to obtain a slope estimate of the annualized percentage change of $\mathrm{FEV}_{1}$ from baseline (\%/year) for each clinically important factor using a multivariable linear mixed model. P-values $<0.05$ were considered statistically significant. For statistical analyses, R statistical software, version 3.6.3 (R Core Team [2020], Vienna, Austria) was used.

\section{Ethics}

This study followed the principles of the Declaration of Helsinki. All included patients submitted their written informed consent at study enrolment. Ethical approval was obtained from the Institutional Review Board Committee of each participating medical center (Seoul National University Seoul Metropolitan Government [SNU-SMG] Boramae Medical Center IRB No. 06-2012-36).

\section{Results}

Of the 1,324 patients with baseline spirometric results, 518 (39.1\%) were followed up with serial spirometric tests for 3 years. Their median annualized percent change from baseline FEV 1 was $-0.3 \% /$ year and the median absolute change in $\mathrm{FEV}_{1}$ was $-4.2 \mathrm{ml} /$ year. Among them, 130 patients met the 
definition of rapid decliners, and the other 388 were classified as non-rapid decliners. Rapid decliners lost $6.2 \%$ and $100 \mathrm{ml}$ of $\mathrm{FEV}_{1}$ every year from their baseline lung function (Figure 1). The annual lung function changes according to a blood eosinophil count in each quartile of change in $\mathrm{FEV}_{1}$ were summarized in Supplementary information 2.

\section{Baseline characteristics and clinical features of rapid and non-rapid decliners}

At baseline, rapid decliners were predominantly men and current or ex-smokers (Table 1). There were no significant differences in symptomatic burden or exacerbation history between rapid and non-rapid decliners.

In terms of spirometric evaluation, we detected no significant differences in post-bronchodilator $\mathrm{FEV}_{1}$ or GOLD grade between rapid and non-rapid decliners (Table 2). However, a higher FVC and lower FEV $1 / F V C$, DLCO, and DLCO/VA values were detected in rapid decliners. In terms of blood tests, there were no differences in white blood cell or differential count. Neither the blood neutrophil/lymphocyte ratio nor the proportion of blood eosinophil counts $\geq 300 / \mu \mathrm{L}$ were significantly related with a rapid decline. Additionally, we discovered no association of radiologic abnormalities such as emphysema, bronchiectasis, and tuberculous-destroyed lung with a rapid decline. In terms of treatment for COPD, rapid decliners more commonly used LABA/LAMA than non-rapid decliners. Other pharmaceutical treatments did not differ between the groups.

In terms of clinical outcomes, rapid decliners exhibited a higher rate of severe exacerbations than nonrapid decliners $(0.2$ /year vs. $0.1 /$ year, $\mathrm{P}=0.032$, Table 3$)$, while overall mortality did not differ between the groups.

\section{Risk factors related to rapid decline}

In the univariable logistic regression model, male sex, low BMI, being a current smoker, a blood eosinophil count $<150 / \mu \mathrm{l}$, a high FVC (\%), a low DLCO (\%), and use of LABA/LAMA were significant risk factors for rapid decline (Table 4). Multivariable logistic regression analysis showed that male sex (odds ratio $[\mathrm{OR}]=3.32 ; 95 \%$ confidence interval $[\mathrm{Cl}]=1.12-9.85)$, being a current smoker $(\mathrm{OR}=1.91 ; 95 \% \mathrm{Cl}=1.17-3.13)$, a blood eosinophil count $<150 / \mu$ l compared to $(\mathrm{OR}=1.96,95 \% \mathrm{Cl}=1.04-3.57)$, and a high FVC (\%) $(\mathrm{OR}=1.03$, $95 \% \mathrm{Cl}=1.01-1.05)$ were independent risk factors for rapid decline.

\section{Clinical factors affecting annualized percentage change of $\mathrm{FEV}_{1}$ from baseline in rapid decliners}

In rapid decliners, sensitivity analysis with a multivariable linear mixed model revealed a rapid annual percentage decline in $\mathrm{FEV}_{1}$ from baseline in current smokers (slope estimate=-2.98, P=0.039) and in patients with a high CAT score (slope estimate $=-0.23, P=0.025$ ) (Table 5). Conversely, taking a combination of inhaled treatments contributed to a rapid annual percentage improvement in $\mathrm{FEV}_{1}$ from baseline. ICS/LABA/LAMA treatment yielded a statistically significantly favorable effect on the annualized percentage change in $\mathrm{FEV}_{1}$ from baseline (slope estimate=3.85, $\mathrm{P}=0.030$ ). 


\section{Discussion}

In the present observational cohort study, we identified that rapid $\mathrm{FEV}_{1}$ decliners are a unique COPD subgroup by investigating the change in $\mathrm{FEV}_{1}$ in Korean patients with COPD over 3 years. In this population, rapid decliners exhibited a higher rate of severe exacerbations of COPD than non-rapid decliners, while 3-year overall mortality did not differ. We revealed that male sex, being a current smoker, a blood eosinophil count $<150 / \mu \mathrm{l}$, and a high FVC (\%) were independent risk factors for a rapid $\mathrm{FEV}_{1}$ decline. Whereas being a current smoker and being more symptomatic (a higher CAT score) were the most statistically significant negative effectors on the annualized percentage change of $\mathrm{FEV}_{1}$ from baseline, taking a combination of inhaled medication, including ICS/LABA/LAMA, was associated with attenuation of that change in rapid decliners. We believe that these results give an important message to clinicians what should do for rapid decliners in COPD patients: abstinence from smoking and symptomatic improvement with combined inhaled bronchodilators should be considered the cornerstones in their treatment.

Many researchers, including Fletcher et al. (21), evaluated the rate of $\mathrm{FEV}_{1}$ decline in patients with COPD as absolute values ( $\mathrm{ml} /$ year). Rapid decliners have previously been defined as patients with a decline in $\mathrm{FEV}_{1} \geq 40(10,22)$ or $\geq 60 \mathrm{ml} /$ year $(23)$. In general, the annual rate of $\mathrm{FEV}_{1}$ decline is larger in patients with early COPD with less pronounced airflow limitation $(12,13)$. Considering that airflow limitation is increased by persistent airway inflammation in patients with $\operatorname{COPD}(1,2)$, it is difficult to explain why the rate of decline in $\mathrm{FEV}_{1}$ is at its highest in mild COPD. Interestingly, the rate of decline in absolute $\mathrm{FEV}_{1}$ ( $\mathrm{ml} /$ year) decreases as the COPD grade increases (13); however, when correcting for the baseline $\mathrm{FEV}_{1}$, the relative rate of $\mathrm{FEV}_{1}$ decline (percentage change from baseline/year) actually increases as the COPD grade increases (24). In our study, we defined rapid decliners as the quartile of patients with the highest annual percentage of $\mathrm{FEV}_{1}$ loss from the baseline value. In our multivariable analysis, the risk of rapid decliner was higher than in GOLD grade II, III, and IV compared to grade I, although statistical significance was not found. Our findings highlight the need of considering the baseline $\mathrm{FEV}_{1}$ values when evaluating the rate of $\mathrm{FEV}_{1}$ decline in patients with COPD.

In our study, the annual rate of hospitalization due to COPD was higher in rapid than in non-rapid decliners, although the causal relationship is not clear. The rate of $\mathrm{FEV}_{1}$ decline may have been more rapid due to severe exacerbations, or there may have been more severe exacerbations in the high-risk group defined as rapid decliners. However, it should be noted that a rapid $\mathrm{FEV}_{1}$ decline was not related with a previous history of exacerbations or symptomatic score, which are well-known predictive factors for exacerbations. Indeed, in a cohort database compiled to evaluate the atherosclerosis risk, a rapid $\mathrm{FEV}_{1}$ decline was related to severe exacerbation and mortality over 8 years of follow-up (11). Therefore, it should be elucidated whether rapid decliners are also a unique subtype of COPD in terms of a poorer prognosis. 
In our study, we demonstrated that the risk of rapid $\mathrm{FEV}_{1}$ decline was higher in patients with COPD with a low blood eosinophil count $(<150 / \mu \mathrm{l})$ compared to those with a high blood eosinophil count $(\geq 300 / \mu \mathrm{l})$. In a recent study, patients with COPD with a blood eosinophil count $\geq 300 / \mu \mathrm{l}$ exhibited an accelerated decline in lung function (25). This discrepancy may be explained by differences in the proportions of ICS users between that study and ours. In that study, the proportion of patients with a blood eosinophil count $\geq 300 / \mu \mathrm{l}$ was $24.3 \%$ and ICS was used by $14.6 \%$ (25), while the proportion with a blood eosinophil count $\geq 300 / \mu \mathrm{l}$ was $21.2 \%$ and ICS was used by $42.9 \%$ in our study. Importantly, in patients with COPD with a high blood eosinophil count, the use of ICS was reported to significantly reduce the rate of lung function decline, while $\mathrm{FEV}_{1}$ decline was more rapid in patients not treated with ICS (18). Additionally, a low blood eosinophil profile is related with a high bacterial burden (26) and emphysema progression (27). Further, a high risk of mortality was observed in patients with COPD with a low blood eosinophil count $(28,29)$. One author speculated that a low blood eosinophil count indicates a phenotype of COPD with neutrophilic inflammation (30). Neutrophilic inflammation in COPD is related with rapid lung function decline and a higher exacerbation rate $(31,32)$. Therefore, patients with COPD with a low blood eosinophil count may constitute a subgroup related to rapid lung function decline because of a poor response to ICS and susceptibility to neutrophilic inflammation.

In the general population, men have a larger lung volume and exhibit a more rapid $\mathrm{FEV}_{1}$ decline than women (33). In our study, men also had a higher risk of rapid decline. However, in another study, a higher proportion of rapid decliners was reported in the female compared to the male population (11). This discrepancy implies that different factors influence the rate of lung function decline in each sex. In mild to moderate COPD, a higher rate of annual FEV 1 decline was related with smoking and obesity in men, but with more severe airway obstruction in women (34). Interestingly, menopause is related to a more rapid $\mathrm{FEV}_{1}$ decline in the female population (35). In patients with asthma, inhaled corticosteroid treatment attenuates lung function decline to a lesser extent in women than in men (36). Thus, the characteristics of rapid decliners should be determined separately in each sex by analysing a larger COPD cohort.

In our study, ICS/LABA/LAMA treatment yielded a potential benefit in reducing the annualized percent change of $\mathrm{FEV}_{1}$ from baseline compared to mono-bronchodilator therapy in rapid decliners. This outcome is consistent with the results of the TRINITY trial, in which ICS/LABA/LAMA treatment was superior to LAMA treatment alone in reducing the change in $\mathrm{FEV}_{1}$ over 52 weeks (37). A recent meta-analysis revealed the superiority of ICS/LABA/LMA treatment in improving trough $\mathrm{FEV}_{1}(\mathrm{~L})$ compared to monobronchodilator therapy (38). In an expert review, triple therapy was recommended for treatment of patients with COPD with a significant lung function decline (39). However, it remains unclear whether ICS/LAMA/LABA treatment reduces lung function decline more than ICS/LABA or LABA/LAMA treatment (40).

Our study is subject to several limitations. First, a selection bias cannot be excluded in our study because our patients were predominantly from tertiary teaching hospitals. Therefore, patients with COPD at high risk of a rapid decline in lung function were more likely to be included in the present study. Second, the 
progression of airflow limitation caused by the natural course of COPD is not the only factor that can affect the median rate of $\mathrm{FEV}_{1}$ decline over 3 years. Although our study revealed that $47.9 \%$ of our patients had an annual increase in $\mathrm{FEV}_{1}$, it would be unreasonable to say that their lung function actually increased every year, because COPD is irreversible and progressive. In particular, when interpreting our results, one should bear in mind the initial improvement in $\mathrm{FEV}_{1}$ that a patient exhibits when starting to use inhaled bronchodilators. A longer-term observational study is needed to overcome this limitation. Finally, we could not obtain data on longitudinal changes in other important clinical factors affecting lung function change, such as BMI, smoking, exercise, and inhalation therapy. Prospective studies need to be conducted in which longitudinal data of such factors are included.

\section{Conclusions}

$\mathrm{A}$ rapid $\mathrm{FEV}_{1}$ decline was related to a higher rate of severe exacerbations. Male sex, being a current smoker, a low blood eosinophil count $(<150 / \mu \mathrm{l})$, and a high FVC \% were independent risk factors for a rapid $\mathrm{FEV}_{1}$ decline. Identification of such risk factors for rapid lung function decline may assist physicians in providing earlier interventions for patients with COPD at high risk.

\section{Abbreviations}

$\mathrm{BMI}$, body mass index; CAT, COPD assessment test; $\mathrm{CCl}$, Charlson comorbidity index; $\mathrm{Cl}$, confidence interval; COPD, chronic obstructive pulmonary disease; DLCO, diffusing capacity for carbon monoxide; $\mathrm{FEV}_{1}$, forced expiratory volume in 1 second; FVC, forced vital capacity; GOLD, Global Initiative for Chronic Obstructive Lung Disease; ICS, inhaled corticosteroid; LABA, long-acting beta-agonist; LAMA, long-acting muscarinic antagonist; OR, odds ratio; SGRQ-C, St George's Respiratory Questionnaire for COPD patients; VA, alveolar volume

\section{Declarations}

\section{Ethics approval and consent to participate}

This study followed the principles of the Declaration of Helsinki. All included patients submitted their written informed consent at study enrolment. Ethical approval was obtained from the Institutional Review Board Committee of each participating medical center (Seoul National University Seoul Metropolitan Government [SNU-SMG] Boramae Medical Center IRB No. 06-2012-36).

\section{Consent for publication}

Not applicable

\section{Availability of data and materials}

Data can be shared or provided upon reasonable request. 


\section{Competing interests}

The authors declare no support from any organization interested with the submitted work, no financial relationship with any organization that might have an interest in the submitted work within the previous 3 years, and no other relationship or activity that could appear to have influenced the submitted work.

\section{Funding}

This work was supported by the Research Program funded Korea National Institute of Health. (Fund CODE 2016ER670100, 2016ER670101, 2016ER670102, 2018ER67100, 2018ER67101, 2018ER67102, and 2021ER120500)

\section{Authors' contributions}

Study concept and design: HWL, DKK

Acquisition of data: all authors

Analysis and interpretation of data: HWL, DKK

Drafting the manuscript: HWL

Critical revision of the manuscript and important intellectual content: all authors

Obtained funding: KHY, DKK

Study supervision: DKK

\section{Acknowledgements}

Not applicable

\section{References}

1. Saetta M, Turato G, Maestrelli P, Mapp CE, Fabbri LM. Cellular and structural bases of chronic obstructive pulmonary disease. American journal of respiratory and critical care medicine. 2001;163(6):1304-9.

2. Barnes PJ. Chronic obstructive pulmonary disease. The New England journal of medicine. 2000;343(4):269-80.

3. Kim WD, Chi HS, Choe KH, Kim WS, Hogg JC, Sin DD. The Role of Granzyme B Containing Cells in the Progression of Chronic Obstructive Pulmonary Disease. Tuberculosis and respiratory diseases. 2020;83(Supple 1):S25-s33. 
4. Vestbo J, Prescott E, Lange P. Association of chronic mucus hypersecretion with FEV1 decline and chronic obstructive pulmonary disease morbidity. Copenhagen City Heart Study Group. American journal of respiratory and critical care medicine. 1996;153(5):1530-5.

5. Donaldson GC, Seemungal TA, Patel IS, Bhowmik A, Wilkinson TM, Hurst JR, et al. Airway and systemic inflammation and decline in lung function in patients with COPD. Chest. 2005;128(4):1995-2004.

6. Chen $\mathrm{CZ}$, Ou CY, Wang WL, Lee $\mathrm{CH}$, Lin CC, Chang HY, et al. Using post-bronchodilator FEV $\mathbb{\text { is }}$ better

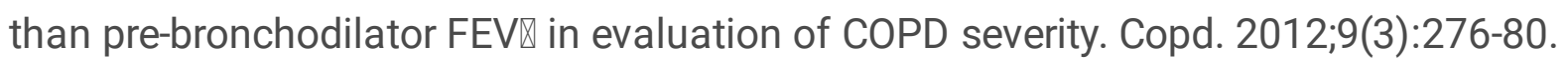

7. Global Initiative for Chronic Obstructive Lung Disease. Global strategy for the diagnosis, management, and prevention of chronic obstructive pulmonary disease. Global Initiative for Chronic Obstructive Lung Disease; 2020 [accessed 2021 April 21]. Available from: http://www.goldcopd.org/.

8. Celli BR, Anderson JA, Cowans NJ, Crim C, Hartley BF, Martinez FJ, et al. Pharmacotherapy and Lung Function Decline in Patients with Chronic Obstructive Pulmonary Disease. A Systematic Review. American journal of respiratory and critical care medicine. 2021;203(6):689-98.

9. Lee HW, Park J, Jo J, Jang EJ, Lee CH. Comparisons of exacerbations and mortality among regular inhaled therapies for patients with stable chronic obstructive pulmonary disease: Systematic review and Bayesian network meta-analysis. PLoS medicine. 2019;16(11):e1002958.

10. Lange P, Celli B, Agustí A, Boje Jensen G, Divo M, Faner R, et al. Lung-Function Trajectories Leading to Chronic Obstructive Pulmonary Disease. The New England journal of medicine. 2015;373(2):111-22.

11. Mannino DM, Reichert MM, Davis KJ. Lung function decline and outcomes in an adult population. American journal of respiratory and critical care medicine. 2006;173(9):985-90.

12. Tantucci C, Modina D. Lung function decline in COPD. International journal of chronic obstructive pulmonary disease. 2012;7:95-9.

13. Bhatt SP, Soler X, Wang X, Murray S, Anzueto AR, Beaty TH, et al. Association between Functional Small Airway Disease and FEV1 Decline in Chronic Obstructive Pulmonary Disease. American journal of respiratory and critical care medicine. 2016;194(2):178-84.

14. Whittaker HR, Pimenta JM, Jarvis D, Kiddle SJ, Quint JK. Characteristics Associated with Accelerated Lung Function Decline in a Primary Care Population with Chronic Obstructive Pulmonary Disease. International journal of chronic obstructive pulmonary disease. 2020;15:3079-91.

15. Tashkin DP, Li N, Halpin D, Kleerup E, Decramer M, Celli B, et al. Annual rates of change in pre- vs. postbronchodilator FEV1 and FVC over 4 years in moderate to very severe COPD. Respiratory medicine. 2013;107(12):1904-11. 
16. Dransfield MT, Kunisaki KM, Strand MJ, Anzueto A, Bhatt SP, Bowler RP, et al. Acute Exacerbations and Lung Function Loss in Smokers with and without Chronic Obstructive Pulmonary Disease. American journal of respiratory and critical care medicine. 2017;195(3):324-30.

17. Donaldson GC, Seemungal TA, Bhowmik A, Wedzicha JA. Relationship between exacerbation frequency and lung function decline in chronic obstructive pulmonary disease. Thorax. 2002;57(10):84752.

18. Kerkhof M, Voorham J, Dorinsky P, Cabrera C, Darken P, Kocks JW, et al. Association between COPD exacerbations and lung function decline during maintenance therapy. Thorax. 2020;75(9):744-53.

19. von Elm E, Altman DG, Egger M, Pocock SJ, Gøtzsche PC, Vandenbroucke JP. The Strengthening the Reporting of Observational Studies in Epidemiology (STROBE) statement: guidelines for reporting observational studies. Lancet (London, England). 2007;370(9596):1453-7.

20. Lee JY, Chon GR, Rhee CK, Kim DK, Yoon HK, Lee JH, et al. Characteristics of Patients with Chronic Obstructive Pulmonary Disease at the First Visit to a Pulmonary Medical Center in Korea: The KOrea cOpd Subgroup Study Team Cohort. Journal of Korean medical science. 2016;31(4):553-60.

21. Fletcher C, Peto R. The natural history of chronic airflow obstruction. British medical journal. 1977;1(6077):1645-8.

22. Vestbo J, Edwards LD, Scanlon PD, Yates JC, Agusti A, Bakke P, et al. Changes in forced expiratory volume in 1 second over time in COPD. The New England journal of medicine. 2011;365(13):1184-92.

23. Marott JL, Ingebrigtsen TS, Çolak Y, Vestbo J, Lange P. Lung Function Trajectories Leading to Chronic Obstructive Pulmonary Disease as Predictors of Exacerbations and Mortality. American journal of respiratory and critical care medicine. 2020;202(2):210-8.

24. Raimondi GA. FEV(1) Decline in Patients with Chronic Obstructive Pulmonary Disease. American journal of respiratory and critical care medicine. 2017;195(12):1676-7.

25. Tan WC, Bourbeau J, Nadeau G, Wang W, Barnes N, Landis SH, et al. High eosinophil counts predict decline in FEV(1): results from the CanCOLD study. The European respiratory journal. 2021;57(5).

26. MacDonald MI, Osadnik CR, Bulfin L, Hamza K, Leong P, Wong A, et al. Low and High Blood Eosinophil Counts as Biomarkers in Hospitalized Acute Exacerbations of COPD. Chest. 2019;156(1):92-100.

27. Singh D, Kolsum U, Brightling CE, Locantore N, Agusti A, Tal-Singer R. Eosinophilic inflammation in COPD: prevalence and clinical characteristics. The European respiratory journal. 2014;44(6):1697-700.

28. Prudente R, Ferrari R, Mesquita CB, Machado LHS, Franco EAT, Godoy I, et al. Peripheral Blood Eosinophils and Nine Years Mortality in COPD Patients. International journal of chronic obstructive pulmonary disease. 2021;16:979-85. 
29. Shin SH, Park HY, Kang D, Cho J, Kwon SO, Park JH, et al. Serial blood eosinophils and clinical outcome in patients with chronic obstructive pulmonary disease. Respiratory research. 2018;19(1):134.

30. Singh D. Blood Eosinophil Counts in Chronic Obstructive Pulmonary Disease: A Biomarker of Inhaled Corticosteroid Effects. Tuberculosis and respiratory diseases. 2020;83(3):185-94.

31. Stănescu D, Sanna A, Veriter C, Kostianev S, Calcagni PG, Fabbri LM, et al. Airways obstruction, chronic expectoration, and rapid decline of FEV1 in smokers are associated with increased levels of sputum neutrophils. Thorax. 1996;51(3):267-71.

32. Gompertz S, O'Brien C, Bayley DL, Hill SL, Stockley RA. Changes in bronchial inflammation during acute exacerbations of chronic bronchitis. The European respiratory journal. 2001;17(6):1112-9.

33. Talaminos Barroso A, Márquez Martín E, Roa Romero LM, Ortega Ruiz F. Factors Affecting Lung Function: A Review of the Literature. Archivos de bronconeumologia. 2018;54(6):327-32.

34. Watson L, Vonk JM, Löfdahl CG, Pride NB, Pauwels RA, Laitinen LA, et al. Predictors of lung function and its decline in mild to moderate COPD in association with gender: results from the Euroscop study. Respiratory medicine. 2006;100(4):746-53.

35. Triebner K, Matulonga B, Johannessen A, Suske S, Benediktsdóttir B, Demoly P, et al. Menopause Is Associated with Accelerated Lung Function Decline. American journal of respiratory and critical care medicine. 2017;195(8):1058-65.

36. Dijkstra A, Vonk JM, Jongepier H, Koppelman GH, Schouten JP, ten Hacken NH, et al. Lung function decline in asthma: association with inhaled corticosteroids, smoking and sex. Thorax. 2006;61(2):105-10.

37. Vestbo J, Papi A, Corradi M, Blazhko V, Montagna I, Francisco C, et al. Single inhaler extrafine triple therapy versus long-acting muscarinic antagonist therapy for chronic obstructive pulmonary disease (TRINITY): a double-blind, parallel group, randomised controlled trial. Lancet (London, England). 2017;389(10082):1919-29.

38. Zheng Y, Zhu J, Liu Y, Lai W, Lin C, Qiu K, et al. Triple therapy in the management of chronic obstructive pulmonary disease: systematic review and meta-analysis. BMJ (Clinical research ed). 2018;363:k4388.

39. Calzetta L, Matera MG, Rogliani P, Cazzola MJERoCP. The role of triple therapy in the management of COPD. 2020;13(8):865-74.

40. Voorham J, Kerkhof M, Georges G, Vezzoli S, Papi A, Vogelmeier C, et al. Comparative Real-World Effectiveness of Triple Therapy Versus Dual Bronchodilation on Lung Function Decline in Frequently Exacerbating Patients with COPD. B45 COPD: TREATMENT: American Thoracic Society; 2019. p. A3314A. 


\section{Tables}

Due to technical limitations, table 1-5 is only available as a download in the Supplemental Files section.

\section{Figures}

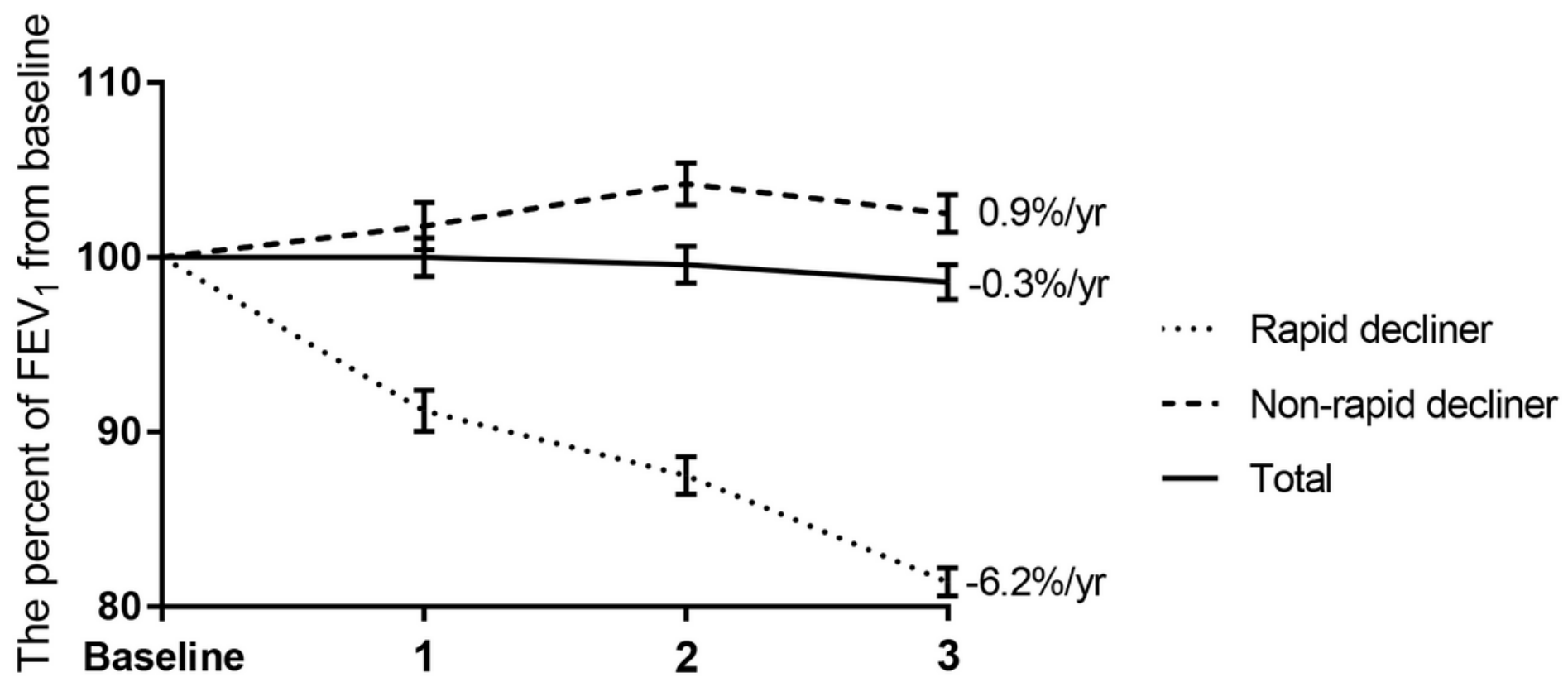

Follow up year

Figure 1

Natural course of FEV1 changes in rapid and non-rapid decliner FEV1, forced expiratory volume in 1 second The annualized percent change of FEV1 from baseline (\%/yr) was estimated in total patients (solid line), rapid decliner (dotted line), and non-rapid decliner (dashed line) with linear regression model.

\section{Supplementary Files}

This is a list of supplementary files associated with this preprint. Click to download.

- STROBEchecklist20210801.docx

- Supplement1DefintionofLineargradient20210623.tif

- Supplement2FEV1 parametersbyquartile20210608.docx

- Table1RapidDeclinerbaseline20210607.pdf

- Table2RapidDeclinerClinicalfeautre20210608.pdf

- Table3RapidDeclinerClinicalOutcome20210525.pdf

- Table4Regressionanalysis20210525.pdf 
- Table5Mixedeffectmodelanalysis20210525.pdf 